\title{
Implementation of a novel portfolio of structured, curriculum-aligned, simulation-based, cardiothoracic surgery training courses: Evolving the delivery of surgical education
}

\author{
Narain Moorjani, MA, MB ChB, MD, FRCS (C-Th), ${ }^{a}$ Michael Lewis, BSc, MB ChB, MD, FRCS (C-Th), \\ Rajesh Shah, MBBS, MS, FRCS (C-Th), ${ }^{c}$ Sion Barnard, MB BCh, MSc, FRCS (C-Th), ${ }^{d}$ \\ Tim Graham, MB ChB, FRCS, FFST Ed, ${ }^{\mathrm{e}}$ and Sridhar Rathinam, MBBS, FRCS (C-Th $)^{\mathrm{f}}$
}

\section{ABSTRACT}

Objective: The provision of high-quality cardiothoracic surgical training faces many challenges. This has generated an increased interest in simulation-based learning, which can provide a less stressful environment for deliberate practice. We developed a comprehensive, structured program of knowledge and simulation-based learning aligned to the official cardiothoracic surgery curriculum.

Methods: A portfolio of 10 curriculum-aligned training courses was designed for cardiothoracic surgical trainees during their 6-year training program. The courses were delivered through a multitude of education methods, including live porcine operating simulation models, and were evaluated through a series of quantitative (5-point Likert-scale) and qualitative assessments. The trainees $(n=15-21$ per course) also completed pre- and postsession self-confidence and competency levels for each training episode of knowledge and skill, respectively. In addition, board examination pass rates were assessed in the 3-year periods before and after implementation of the courses.

Results: Quantitative analysis of the trainees' feedback demonstrated an extremely positive view of the portfolio of the simulation-based training courses with excellent satisfaction scores (out of 5) for teaching sessions (4.44 \pm 0.07 ), faculty (4.64 \pm 0.07$)$, content and materials (4.63 \pm 0.07$)$, and facilities $(4.73 \pm 0.05)$. The courses have shown a significant improvement in the post-self-confidence $(7.98 \pm 0.13$ vs $5.62 \pm 0.20, P<.01)$ and perceived self-competency $(8.10 \pm 0.10$ vs $5.67 \pm 0.11, P<.01)$ scores for all courses. Examination pass rates significantly improved in the 3-year period after attendance at the courses $(94.82 \% \pm 2.34 \%$ vs $76.26 \% \pm 3.23 \%, P<.005)$.

Conclusions: This study has described the implementation of the only extensive program of structured simulation-based courses that has been developed to complement clinical training in cardiothoracic surgery. ( $\mathrm{J}$ Thorac Cardiovasc Surg 2017;154:2009-16)

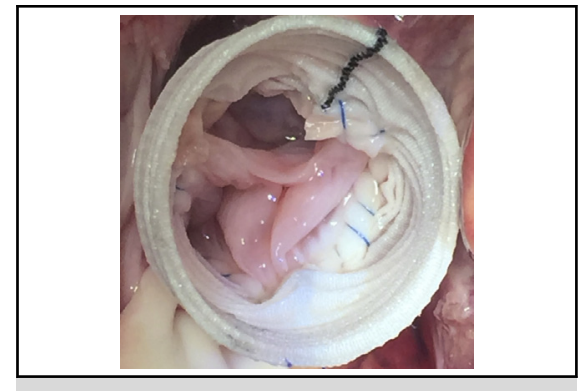

Valve-sparing aortic root replacement performed on the live operating simulation model.

\section{Central Message}

This study has described the implementation of the only extensive portfolio of structured, simulation-based courses that have been developed to complement clinical training in cardiothoracic surgery.

\section{Perspective}

This study describes the implementation of an extensive program of structured, simulationbased courses that allows trainees to develop technical and nontechnical skills in a less stressful, safe environment, with the opportunity for deliberate practice. This is associated with a significant increase in trainees' selfconfidence of knowledge and self-perception of competency in technical skills.

See Editorial Commentary page 2017.

See Editorial page 2007.

\footnotetext{
From the ${ }^{\mathrm{a}}$ Department of Cardiothoracic Surgery, Papworth Hospital, Cambridge; ${ }^{\mathrm{b}}$ Department of Cardiothoracic Surgery, Royal Sussex County Hospital, Brighton; ${ }^{\mathrm{c}}$ Department of Cardiothoracic Surgery, Wythenshawe Hospital, Manchester; ${ }^{\mathrm{d}}$ Department of Cardiothoracic Surgery, Freeman Hospital, Newcastle; ${ }^{\mathrm{e}}$ Department of Cardiothoracic Surgery, Queen Elizabeth Hospital, Birmingham; and ${ }^{\mathrm{f}}$ Department of Thoracic Surgery, Glenfield Hospital, Leicester, United Kingdom. Ethicon Inc (Somerville, NJ) provided financial support for the equipment, venue, travel, and accommodation of the trainees and faculty.
}

Received for publication Dec 8, 2016; revisions received July 5, 2017; accepted for publication July 27, 2017; available ahead of print Sept 26, 2017.

Address for reprints: Narain Moorjani, MA, MB ChB, MD, FRCS (C-Th), Department of Cardiothoracic Surgery, Papworth Hospital, Papworth Everard, Cambridge CB23 3RE, United Kingdom (E-mail: narain.moorjani@nhs.net). $0022-5223 / \$ 36.00$

Crown Copyright (C) 2017 Published by Elsevier Inc. on behalf of The American Association for Thoracic Surgery

http://dx.doi.org/10.1016/j.jtcvs.2017.07.075 


\section{Abbreviation and Acronym \\ SCTS $=$ Society for Cardiothoracic Surgery in Great Britain and Ireland}

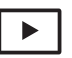

Scanning this $Q R$ code will take you to a supplemental video for the article.

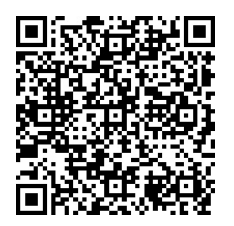

Provision of high-quality cardiothoracic surgical training faces many challenges because of the changing clinical environment in which education is delivered. This includes restrictions on working hours, publication of surgeon specific mortality, patient safety issues, trainees with less experience entering the specialty, and more complex operations in patients with multiple comorbidities. ${ }^{1,2}$ Associated with this, there has been a shift in the methodology of training from an apprenticeship model, in which a trainee was guided by a mentor into the craftsmanship of surgery, to a less-structured model for the transmission of knowledge and skills to the trainee. ${ }^{3}$ Furthermore, the "see one, do one, teach one" philosophy, in which a trainee's first attempt to perform a procedure is on a patient, is no longer acceptable. ${ }^{4}$ This has generated an increased interest in the use of simulation-based learning to tackle these challenges in cardiothoracic surgical training.

Simulation-based education is able provide a less stressful environment for trainees to encounter a complete cycle of learning, including direct experience, reflection, conceptualization, and opportunity to experiment. ${ }^{5}$ This cycle creates an opportunity for deliberate practice, which is an education technique that uses steps of repetition, assessment, and feedback, resulting in an improvement of performance. ${ }^{6}$ This is in stark contrast to the operating room, where clinical and service provision needs restrict the time and opportunity for practice and reflection. Simulation-based learning gives trainees the opportunity to acquire technical skills to complement their learning in the clinical arena but without compromising patient safety. ${ }^{7}$ Simulated-learning provides standardized and reproducible learning experiences for trainees that can be adapted to a variety of clinical conditions and complications to encompass both technical and nontechnical skills. 8

Structured simulation-based training can result in a significant improvement in the operative performance of surgeons on patients. ${ }^{10}$ The widespread adoption of simulation-based learning has been limited because of availability of faculty in terms of the time and commitment, financial pressures related to the cost of the facilities and equipment, and the absence of a structured curriculum of simulation-based learning in cardiothoracic surgery. ${ }^{11}$

Currently, clinical experience gained during cardiothoracic surgery training programs varies widely. In an attempt to bridge the gap and standardize the core knowledge of junior surgeons progressing through their training years, we developed a comprehensive, structured program of knowledge and simulation-based learning, aligned to the official cardiothoracic surgery curriculum.

\section{METHODS AND MATERIALS Curriculum Design}

A stepwise approach was used to develop the simulation-based curriculum, first by performing a needs assessment to determine the core knowledge and skills that are required by cardiothoracic surgical trainees progressing through their 6-year training program. ${ }^{12}$ This was achieved by reviewing the Royal College of Surgeons cardiothoracic surgery curriculum and full engagement and collaboration of the key stakeholders involved in cardiothoracic surgery training, including the Cardiothoracic Surgery Specialty Advisory Subcommittee of the Joint Royal Surgical Colleges Training Committee and training program directors, as well as extensive discussions with current cardiothoracic surgical specialty trainees.

Once documented, each of the individual core knowledge and skills categories was divided into 5 groups: acquired cardiac surgery, general thoracic surgery, congenital cardiac surgery, intensive care management, and professional development. To ensure the maximum benefits for the trainees, their exact needs at the different stages of their training program were then determined. This allowed an overall program of 10 structured courses to be created and delivered over the 6-year training program (Figure 1). The learning objectives of each course were then created, ensuring that the core knowledge and skills delivered were appropriate to the seniority of the trainee. The course content varied but covered technical skills, case-based discussion management of common clinical scenarios and evaluation of acutely ill patients, nontechnical skills, and matters of professional development pertaining to the practice of a cardiothoracic surgeon.

\section{Education Methodology}

The courses were delivered through a multitude of education techniques, including interactive small group (usually $\leq 4$ ) sessions and simulation-based models, including low-fidelity, low-cost synthetic simulators; high-fidelity computerized simulators; cadaveric or animal tissue-based "wet-lab" simulation models; and live animal operating simulation models.

Low-fidelity, low-cost synthetic simulators were used to recreate the steps involved in a procedure, such as the Arroyo coronary anastomosis simulator (Ethicon Inc, Somerville, NJ), which uses latex tubing to represent the coronary artery and the saphenous vein. As well as the feedback and suggestions for improvement given during the course by the supervising faculty member, this simulator was given to each trainee to be taken home where the trainee can take some ownership of their own training to allow repeated practice and self-reflection. In addition, this was enhanced with simple video-recording facilities, such as using their ubiquitous smart phones or digital cameras, to allow replay and self-critical appraisal.

High-fidelity computerized simulators were also used, such as the Orpheus cardiopulmonary bypass simulator (ULCO Technologies, 


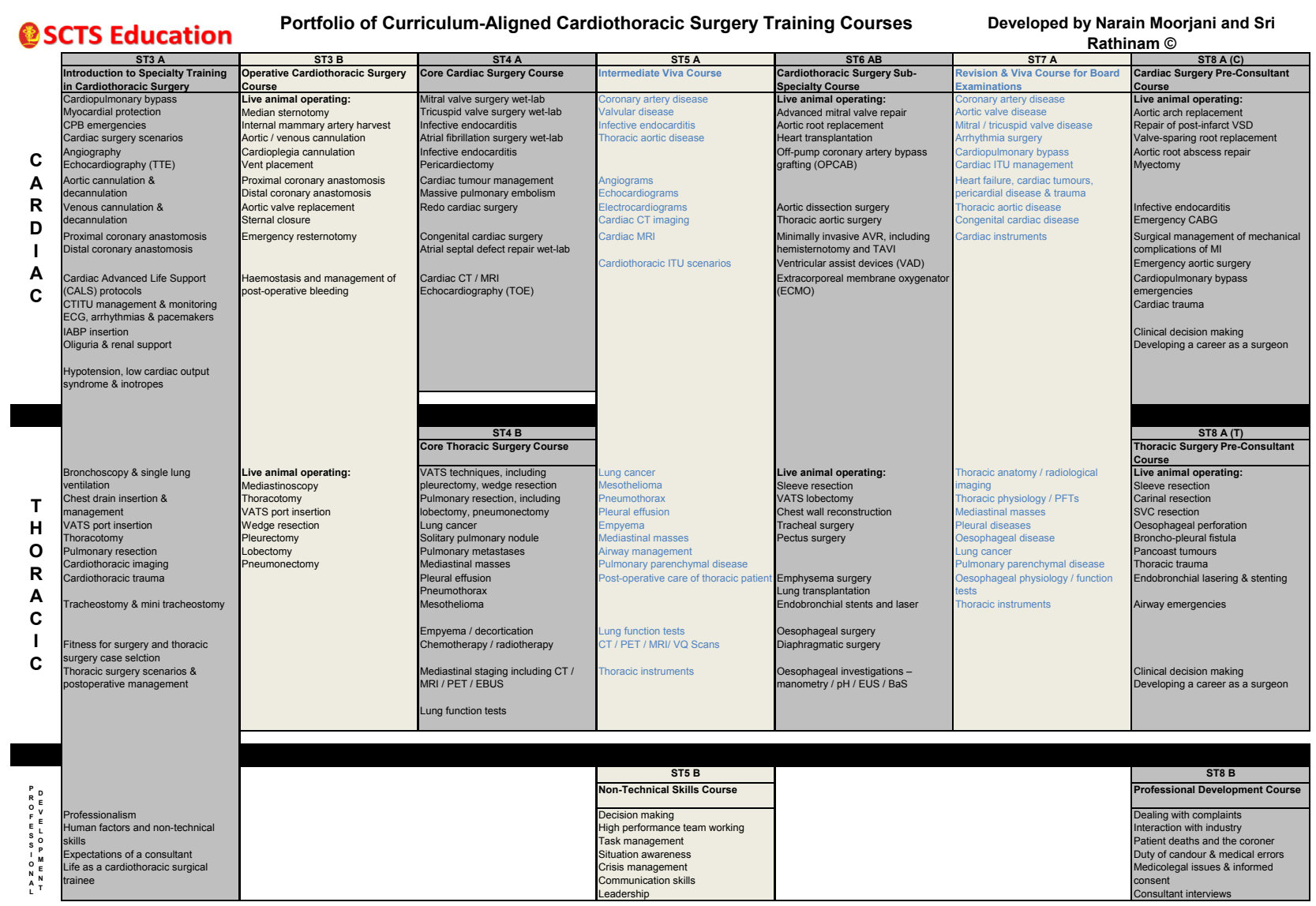

FIGURE 1. Portfolio of structured, curriculum-aligned, simulation-based cardiothoracic surgery training courses. SCTS, Society for Cardiothoracic Surgery in Great Britain and Ireland; $C P B$, cardiopulmonary bypass; TTE, trans-thoracic echocardiography; CTITU, cardiothoracic intensive therapy unit; $E C G$, electrocardiogram; IABP, intra-aortic balloon pump; VATS, video-assisted thoracoscopic surgery; $C T$, computed tomography; $M R I$, magnetic resonance imaging; TOE, trans-oesophageal echocardiography; $P E T$, positron emission tomography; EBUS, endobronchial ultrasound; ITU, intensive therapy unit; $V Q$, ventilation perfusion; $A V R$, aortic valve replacement; $T A V I$, trans-catheter aortic valve implantation; $E U S$, endoscopic ultrasound; $B a S$, barium swallow; PFT, pulmonary function tests; VSD, ventricular septal defect; $C A B G$, coronary artery bypass grafting; $S V C$, superior vena cava.

Marrickville, Australia), which includes a plastic thorax model, connected to a real bypass machine, anesthetic machine, and monitoring. A computer program was used to recreate bypass or operative scenarios, where the patient parameters were altered in real-time to teach nontechnical skills, including situation awareness, leadership, team working, decision-making, and crisis management. In addition, the simulator taught technical skills of instituting and weaning from cardiopulmonary bypass, as well as the management of the complications of bypass and emergency scenarios. In addition, a thoracic virtual reality simulator (Surgical Science, Gothenburg, Sweden) was used to train basic thoracoscopic skills and offer feedback, as well as to train them in thoracoscopic lobectomy. The ability of the virtual-reality model to have an instructor mode, where the trainer can control and create operative ease and difficulties, allows it to be used for teaching both technical and nontechnical skills.

Cadaveric or animal "wet-lab" tissue was used to demonstrate a number of technical skills with clearly defined steps of the procedure, including aortic and venous cannulation, coronary anastomosis, valve repair and replacement, thoracic aortic replacement, pulmonary resection, video-assisted thoracoscopic surgical techniques, and chest wall resection. The highest-fidelity and most realistic simulation model used was the live porcine operating model, where the principles of surgical access, initiating and weaning from cardiopulmonary bypass, and the complete spectrum of cardiac surgical procedures, including off-pump coronary artery bypass grafting, mitral valve repair surgery, valve-sparing aortic root replacement (Figure 2), postinfarct ventricular defect repair, and aortic arch replacement, can be taught and performed (Video 1). Likewise, complex thoracic surgical procedures, including video-assisted thoracoscopic surgery lobectomy, sleeve resections, tracheal resection, and laser procedures, were performed in the live porcine operating model. Throughout these procedures, the trainees wore surgical scrubs, hats, masks, and gloves, as well as properly prepping and draping the thorax in a standard fashion to recreate the operating room experience. All procedures were carried out in full accordance of local ethical protocols.

All these skills were taught using the principles of deliberate practice with repetition, assessment, and feedback via direct observation and mentoring from a member of the teaching faculty. All members of the faculty had been taught the principles of education delivery, having undergone a "Training the Trainers" course, allowing them to give constructive structured feedback providing the ideal environment for improvement in performance.

\section{Delegates}

Every nationally appointed cardiothoracic surgical trainee was invited to attend the 10 courses over their 6-year training program. Between 15 and 21 trainees attend each course, with a total of 187 delegates attending 


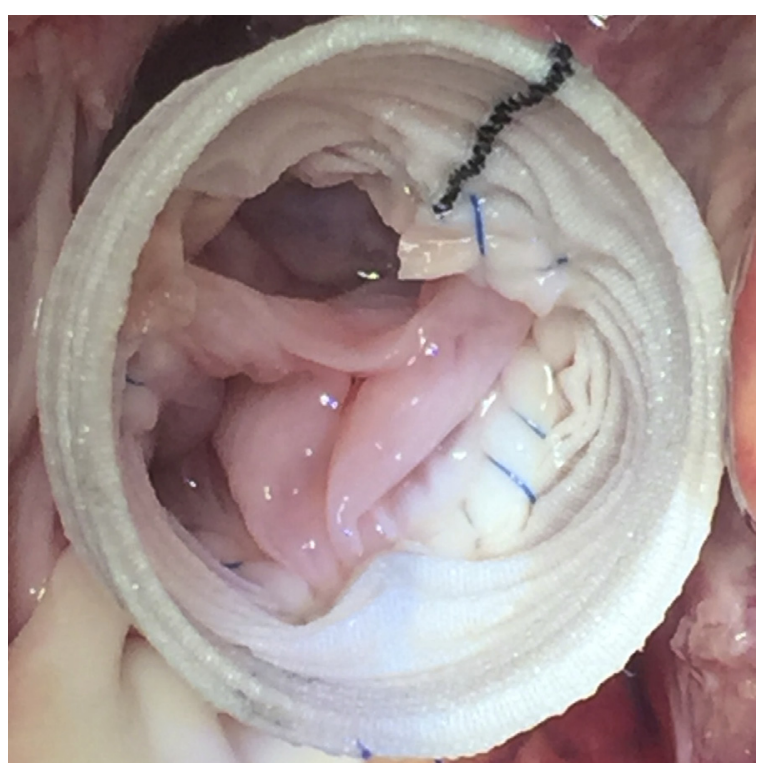

FIGURE 2. Valve-sparing aortic root replacement performed on the live operating simulation model.

the 10 courses over the 12-month cycle (Table 1). These trainees came from all 39 cardiothoracic surgical units within the United Kingdom and Republic of Ireland. The faculty teaching on the courses came from 33 of the 39 cardiothoracic units.

\section{Course Program}

The courses in the first year served as an introduction to specialty training in cardiothoracic surgery, including performing appropriate technical skills, important aspects of intensive care management and practice of surgical access, and placing a patient on cardiopulmonary bypass on a live animal model. The trainees are then taught the knowledge and skills of core cardiac and thoracic surgery before attending an intermediate viva course. This assesses the trainees' knowledge in the middle of their training program to ensure a process of continued learning rather than the previous model in which trainees usually left acquisition of knowledge to their final year just before their specialty examinations. This is followed by a course that teaches the principles of nontechnical skills, such as decision-making, leadership, team-working, and situational awareness, using the high-fidelity Orpheus simulator. The second half of the program includes teaching the aspects of the cardiac and thoracic subspecialties on the live operating simulation model, followed by an examination revision course that teaches the core knowledge of the entire syllabus before testing the trainees' knowledge. The final year of the program teaches the principles of emergency cardiac and thoracic surgery on a live operating simulation model, as well as a professional development course. To deliver the portfolio of courses, we obtained financial support of industry, notably from Ethicon Inc (Somerville, NJ), to allow the trainees to attend all of the courses free of charge, with registration, accommodation, and travel costs for all of the trainees and faculty covered by an educational grant. Ethicon also provided the use of their facilities and equipment at the venues.

\section{Assessment}

The courses were assessed through a series of quantitative modified 5 -point Likert scale $(1=$ poor, $5=$ excellent $)$ questions, as well as a free-text comment section regarding the strength and weaknesses of the course and suggestions for improvement. These questions assessed the teaching sessions, faculty, content and materials, and organization and facilities. This allowed the courses to evolve from year to year, being

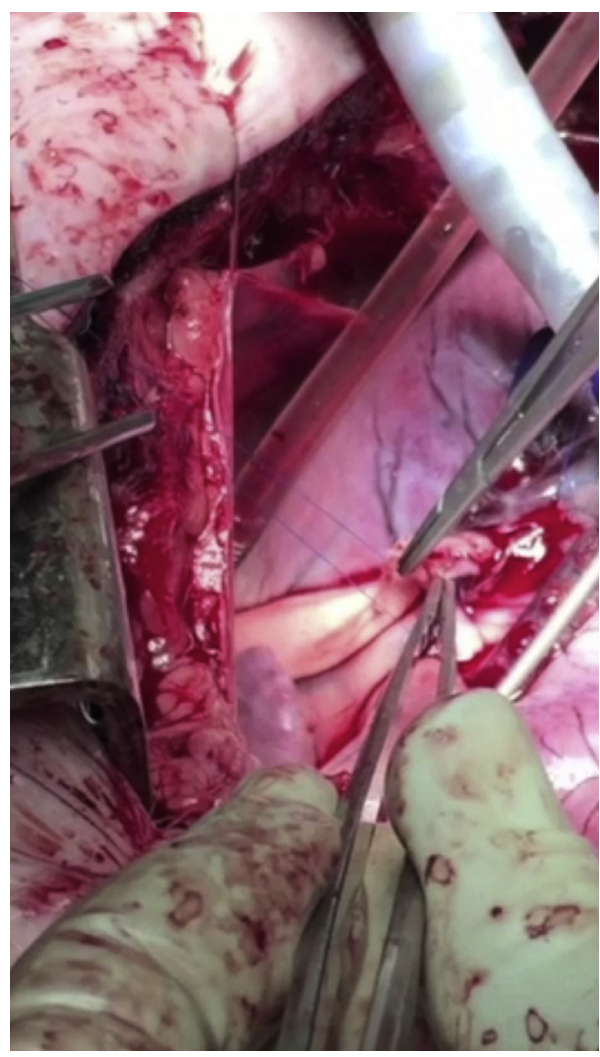

VIDEO 1. Short video illustrating some of the operative procedures performed by cardiothoracic surgical trainees on a live operating simulation model. Video available at: http://www.jtcvsonline.org/article/ S0022-5223(17)31766-X/fulltext.

responsive to the trainees' needs. In addition, the trainees were asked to complete pre- and postsession confidence and competency levels for each teaching episode of knowledge and skill, respectively. Perceived confidence and competency were assessed using a 10-point scale $(1=$ not confident/competent to $10=$ extremely confident/competent $)$. These data were filled in contemporaneously during the course and collected at the end of the course. In addition, as an objective assessment of the clinical knowledge being taught on the courses, the pass rate of the trainees undertaking FRCS (C-Th) board examination was analyzed in the 3 years after implementation of the courses, compared with the 3 years before trainees attended the courses.

\section{Statistical Analysis}

Descriptive statistics were expressed as mean \pm standard error, and comparisons were made using a $t$ test. The data were analyzed using the Statistical Package for the Social Sciences (version 23.0; SPSS Inc, Chicago, Ill).

\section{RESULTS}

Quantitative analysis of the trainees' feedback demonstrated an extremely positive view of the portfolio of simulation-based training courses with excellent satisfaction scores. The courses averaged highly for the quality of teaching sessions, faculty, content and materials, and organization and facilities (Table 1). In particular, the courses with access to the live operating simulation 
TABLE 1. Quantitative assessment of teaching sessions, faculty, content and materials, and organization and facilities, using a modified 5-point Likert scale $(1=$ poor, 5 = excellent)

\begin{tabular}{|c|c|c|c|c|c|c|c|}
\hline Year & Level & Course & $\begin{array}{c}\text { No. of } \\
\text { trainees }\end{array}$ & $\begin{array}{l}\text { Teaching } \\
\text { sessions }\end{array}$ & Faculty & $\begin{array}{c}\text { Content and } \\
\text { materials }\end{array}$ & $\begin{array}{l}\text { Organization } \\
\text { and facilities }\end{array}$ \\
\hline 1 & ST3A & Introduction to Specialty Training in CTS & 20 & $4.38 \pm 0.07$ & $4.76 \pm 0.04$ & $4.84 \pm 0.02$ & $4.80 \pm 0.06$ \\
\hline 1 & ST3B & Operative Cardiothoracic Surgery Course & 21 & $4.42 \pm 0.05$ & $4.76 \pm 0.02$ & $4.74 \pm 0.02$ & $4.74 \pm 0.02$ \\
\hline 2 & ST4A & Core Cardiac Surgery & 19 & $4.03 \pm 0.09$ & $4.16 \pm 0.19$ & $4.13 \pm 0.10$ & $4.62 \pm 0.10$ \\
\hline 2 & ST4B & Core Thoracic Surgery & 16 & $4.33 \pm 0.04$ & $4.59 \pm 0.05$ & $4.63 \pm 0.03$ & $4.76 \pm 0.05$ \\
\hline 3 & ST5A & Intermediate Revision and Viva Course & 15 & $4.24 \pm 0.04$ & $4.42 \pm 0.04$ & $4.26 \pm 0.07$ & $4.60 \pm 0.07$ \\
\hline 3 & ST5B & Nontechnical Skills Course & 16 & $4.54 \pm 0.05$ & $4.50 \pm 0.08$ & $4.66 \pm 0.04$ & $4.42 \pm 0.19$ \\
\hline 4 & ST6AB & Cardiac and Thoracic Subspecialty Course & 21 & $4.27 \pm 0.05$ & $4.70 \pm 0.05$ & $4.87 \pm 0.02$ & $4.96 \pm 0.02$ \\
\hline 5 & ST7A & Revision and Viva Course for Board Examinations & 18 & $4.59 \pm 0.04$ & $4.77 \pm 0.03$ & $4.64 \pm 0.02$ & $4.87 \pm 0.03$ \\
\hline 6 & ST8A & Cardiac and Thoracic Surgery Preconsultant Course & 21 & $4.72 \pm 0.03$ & $4.86 \pm 0.04$ & $4.71 \pm 0.05$ & $4.81 \pm 0.07$ \\
\hline 6 & ST8B & Professional Development Course & 20 & $4.68 \pm 0.05$ & $4.59 \pm 0.03$ & $4.76 \pm 0.02$ & $4.62 \pm 0.16$ \\
\hline
\end{tabular}

CTS, Cardiothoracic surgery.

model rated highest, scoring $4.53 \pm 0.12$ for quality of teaching sessions, $4.82 \pm 0.06$ for faculty, $4.76 \pm 0.04$ for content and materials, and $4.83 \pm 0.05$ for organization and facilities. The assessment process also sought to determine the trainees' self-confidence of knowledge, before and after the interactive small group teaching sessions, and self-perception of competence of a procedure or operation after a simulation-based technical skill session. The courses showed a significant improvement in the pre- and post-self-confidence and perceived self-competency scores $(P<.001)$ (Table 2$)$ for all sessions.

In addition, qualitative data were collected where the trainees were encouraged to openly express their thoughts on the strengths and weaknesses of the course, as well as suggestions for improvement. The trainees collectively commented that the use of surgical simulation models provided excellent training opportunities and in particular because of the opportunity for deliberate practice. They thought that the simulation models were realistic and allowed them to learn a new skill or practice an already acquired skill though a series of repeatable steps, especially those who were encountering difficulty obtaining educational opportunities during their training program. A specific comment from the trainees when performing the procedures on the live operating simulation model was that once the cardiopulmonary bypass had been commenced they felt as if they were engaged in a "real" operation. Several of the trainees commented that the high faculty to trainee ratio (1:2) allowed them to ask questions freely in a safe, open environment, with a culture conducive to learning. All trainees felt better equipped to tackle the clinical duties and operative procedures with patients after attendance at the course and that they had learned many new skills. Of note, they commented that they would recommend the courses to their peers.

The faculty feedback reflected on the enjoyable opportunity for them to teach in an environment without the pressures of theatre throughput or interruptions, and where patient safety was not an issue. In particular, the faculty commented that specific learning objectives could

TABLE 2. Pre- and postsession self-confidence and self-competence levels, using a 10-point scale $(1=$ not confident/competent and $10=$ extremely confident/competent)

\begin{tabular}{lllccccc}
\hline & & & \multicolumn{1}{c}{ Course } & \multicolumn{2}{c}{ Self-confidence } & \multicolumn{2}{c}{ Self-competence } \\
\cline { 5 - 7 } Year & Level & & No. of trainees & Presession & Postsession & Presession & Postsession \\
\hline 1 & ST3A & Introduction to Specialty Training in CTS & 20 & $5.64 \pm 0.11$ & $7.95 \pm 0.07$ & $5.83 \pm 0.22$ & $7.93 \pm 0.08$ \\
\hline 2 & ST4A & Core Cardiac Surgery & 19 & $5.19 \pm 0.12$ & $7.48 \pm 0.14$ & $5.25 \pm 0.16$ & $7.96 \pm 0.12$ \\
\hline 2 & ST4B & Core Thoracic Surgery & 16 & $5.73 \pm 0.17$ & $7.94 \pm 0.14$ & $5.20 \pm 0.36$ & $7.60 \pm 0.27$ \\
\hline 3 & ST5A & Intermediate Revision and Viva Course & 15 & $4.67 \pm 0.28$ & $7.48 \pm 0.09$ & \\
3 & ST5B & Nontechnical Skills Course & 16 & $5.37 \pm 0.37$ & $8.40 \pm 0.10$ & $5.91 \pm 0.13$ & $8.44 \pm 0.10$ \\
\hline 4 & ST6AB & Cardiac and Thoracic Subspecialty Course & 21 & $5.84 \pm 0.14$ & $7.98 \pm 0.08$ & $6.15 \pm 0.19$ & $8.20 \pm 0.18$ \\
\hline 5 & ST7A & Revision and Viva Course for Board Examinations & 18 & $4.98 \pm 0.16$ & $7.53 \pm 0.12$ & & \\
\hline 6 & ST8A & Cardiac and Thoracic Surgery Preconsultant Course & 21 & $6.59 \pm 0.19$ & $8.52 \pm 0.10$ & $5.67 \pm 0.17$ & $8.30 \pm 0.26$ \\
\hline
\end{tabular}

CTS, Cardiothoracic surgery. 
be set and taught through predetermined, important, or rarely encountered clinical or operative scenarios.

The feedback was particularly important for the courses to evolve and for suggestions made by the trainees to be incorporated into future iterations of each course or for generic learning points to be included in all the courses. As one would expect from a cohort of surgical trainees, there were requests to increase the number of simulation sessions, but this needs to be tempered with the requirement to balance simulated technical skills sessions with interactive small group sessions teaching core knowledge.

Overall, the trainees expressed their gratitude to the Society for Cardiothoracic Surgery in Great Britain and Ireland (SCTS) Education for their time and effort providing them with a wealth of training opportunities that were not available to their predecessors, to other cardiothoracic trainees worldwide, or to trainees in other surgical specialties.

Assessment of FRCS (C-Th) board examination pass rates in the 3 years after attendance at the courses demonstrated a significant improvement compared with the 3 years before implementation of the courses $(94.82 \% \pm 2.34 \%$ vs $76.26 \% \pm 3.23 \%, P<.005)$. In addition, during the 3 -year period after implementation of the courses, the pass rate for the board examinations for the cohort of trainees (nationally appointed) who attended the course was significantly higher than the cohort of trainees (non-nationally appointed) who did not attend the courses $(94.82 \% \pm 2.34 \%$ vs $52.20 \% \pm 6.25 \%$, $P<.001)$.

\section{DISCUSSION}

Simulation-based learning has become an important part of the evolving landscape in the delivery of education in cardiothoracic surgery. ${ }^{13}$ It allows the acquisition of surgical skills to be gained in a safe, controlled environment of the simulation laboratory to complement skills learned in the operating theatre. ${ }^{5}$ In this study, we have described the development and implementation of a comprehensive, structured portfolio of 10 simulation-based cardiothoracic training courses aligned to the Royal College of Surgeons Cardiothoracic Surgery curriculum. The portfolio of courses imparted knowledge and allowed trainees to develop and refine technical skills through a variety of simulation-based techniques. To the best of our knowledge, it is the first and only extensive program of structured simulation-based courses that have been developed to complement clinical training in cardiothoracic surgery or in any surgical specialty.

The portfolio of courses, with simulation-based teaching, has given the trainees a better exposure to the concepts and practical details of the taught technical skills than previous didactic teaching that they had encountered. It allowed them to develop skills in a less-stressful, safe environment, where they were allowed to practice, experiment, and even make mistakes.

This study demonstrated a significant increase in trainees' self-confidence in knowledge and self-perception of competency of technical skills after the sessions. These findings are consistent with previous studies that have demonstrated that structured simulation-based teaching sessions improve the confidence level of participants. ${ }^{14}$ In turn, self-confidence has been shown to be associated with increased trainee motivation and achievement, because trainees' behavior is determined by their beliefs about their own capabilities. ${ }^{15}$ Thus, trainees who have had the opportunity to deliberately practice technical and nontechnical skills in the less-stressful environment of the simulation laboratory are able to perform these skills on a patient with more confidence and less anxiety. This has the benefit of increasing the confidence of the trainees when dealing with similar scenarios with patients in a clinical setting. ${ }^{15}$

Despite the many training opportunities and benefits to patient safety, simulation-based learning has yet to gain widespread acceptance and become an established component of contemporary cardiothoracic surgery training programs. ${ }^{14}$ Initially, concerns regarding how realistic the simulation models were and how reliably they could demonstrate a series of components of a procedure engendered a reluctance to engage in simulation-based training, especially that the simulators do not reproduce the same response seen in human disease. With improving fidelity of simulation models, some of these concerns can be dispelled, especially with live large animal operating models, where once prepped and draped, the procedure almost identically mirrors that encountered in a human patient. However, the development and implementation of these models, especially live operating models, can be costly and require considerable financial investment. These costs have been passed on to the delegates and, because trainees need to attend several clinical, simulation, and professionalism courses, can add up to a significant financial burden. ${ }^{16}$ This has been eased because of the association with industry partners. However, the interaction with industry needs to balance the delivery of education while steering clear of any conflict of interest. ${ }^{17}$ In our portfolio of courses, the educational content, learning objectives, course delivery, and recruitment of faculty were organized by the National Cardiac and Thoracic Surgical Tutors (NM, SR), with no influence from industry. The data reported in this study validate the simulation-based curriculum but are not being used in any way to provide marketing of any product or validate any commercial simulation devices.

Another major restraint to the widespread use of simulation-based training is the availability of suitable faculty to teach on the courses. ${ }^{11}$ It requires a significant 
commitment from surgeons who already have many competing interests for their time. We have been fortunate because of the great commitment of established cardiothoracic surgeons to give up their free time to teach the courses. In addition, we have been given support and encouragement from the SCTS to pursue this unique opportunity to deliver the portfolio of training courses, and the SCTS provided us surgeons to teach as faculty on the courses.

This curriculum should be considered the first draft with plans to continually evolve and improve it. Quality assurance is being provided both internally from SCTS Education and externally from the Department of Education at the Royal College of Surgeons of Edinburgh, with changes made on the basis of feedback from the trainees, faculty members, and educationalists who we have involved in assessing the courses. Initial results demonstrate that the concept of a portfolio of simulationbased, curriculum-aligned training courses is feasible and delivers great educational value in terms of stages 1 and 2 of Miller's pyramid of education delivery, namely, reaction and learning. ${ }^{18}$ All trainees and faculty were in agreement that the courses should be a mandatory part of all training programs throughout the country. The major challenge is to continue to maintain the funding stream for the courses and to ensure faculty attendance, currently on a voluntary basis. We are planning to measure immediate and longitudinal outcomes of the courses in relation to clinical practice. Moving forward, in addition to the live operating simulation model, we plan to use simulation models with increased fidelity, including better haptics and tactile feedback.

\section{Study Limitations}

The improvement of board examination pass rates in the 3 -year period after implementation, compared with the 3 -year period before or the non-nationally appointed cohort of trainees who did not attend the courses, may be related to other external factors, but it is important to note that the major change in cardiothoracic surgical education over this time period was the introduction of the portfolio of courses. The use of self-assessment also has several limitations that can lead to an increased or decreased appreciation of one's knowledge or skills. In addition, the positive educational experience of the training course may in itself lead to the increased perception of knowledge and skills in the postcourse self-assessment. Although there are limitations of simulation-based training, including realism and fidelity, it is important to understand that simulation-based training courses are there to complement training that occurs in the operating theatre on patients, which provides the most realistic, highest-fidelity experience for the trainees. Determination of whether these courses ultimately have any impact on patient outcomes may prove to be difficult because of the numerous factors that are involved in the clinical outcome of a patient.

\section{CONCLUSIONS}

This study describes the development of a structured portfolio of curriculum-aligned, simulation-based training courses, which have the central tenet of patient safety at the foundation, allowing trainees to develop technical skills in a less-stressful environment through a process of deliberate practice.

\section{Conflict of Interest Statement}

Authors have nothing to disclose with regard to commercial support.

The authors thank Ross Campbell, Ludwig Groebler, Hannes Uhl, John Bassford, Yvonne Hurst, Fouad Taghavi, Sarah Blackbrough, Shelley Hawkins, Scott Withecombe, and Richard Bourne for the help in setting up these courses; Ethicon Inc (Somerville, NJ) for funding the project and providing the logistical support for the courses; and all the faculty members, who have given up their valuable time and effort to voluntarily teach these courses, without whom this unique educational project would not have been possible.

\section{References}

1. Smelt J, Soppa G, Nowell JL, Barnard S, Jahangiri M. A survey of cardiothoracic surgical training in the United Kingdom: realities of a 6-year integrated training program. Ann Thorac Surg. 2015;100:2314-9.

2. Moffatt-Bruce SD, Nguyen MC, Fann J, Westaby S. Our new reality of public reporting: shame rather than blame? Ann Thorac Surg. 2016;101:1255-61.

3. Baker CJ, Sinha R, Sullivan ME. Development of a cardiac surgery simulation curriculum: from needs assessment results to practical implementation. J Thorac Cardiovasc Surg. 2012;144:7-16.

4. Gillinov M, Mick S, Mihaljevic T, Suri RM. Watch one, do one, teach one. J Thorac Cardiovasc Surg. 2016;151:1506-7.

5. Kirkman MA. Deliberate practice, domain-specific expertise, and implications for surgical education in current climes. J Surg Educ. 2013;70:309-17.

6. Price J, Naik V, Boodhwani M, Brandys T, Hendry P, Lam BK. A randomized evaluation of simulation training on performance of vascular anastomosis on a high-fidelity in vivo model: the role of deliberate practice. J Thorac Cardiovasc Surg. 2011;142:496-503.

7. Feins RH, Burkhart HM, Conte JV, Coore DN, Fann JI, Hicks GL Jr, et al. Simulation-based training in cardiac surgery. Ann Thorac Surg. 2017;103:312-21.

8. Hicks GL Jr, Gangemi J, Angona RE Jr, Ramphal PS, Feins RH, Fann JI Cardiopulmonary bypass simulation at the Boot Camp. J Thorac Cardiovasc Surg. 2011;141:284-92.

9. Yule S, Paterson-Brown S. Surgeons' non-technical skills. Surg Clin North Am 2012;92:37-50.

10. Palter VN, Grantcharov T, Harvey A, Macrae HM. Ex vivo technical skills training transfers to the operating room and enhances cognitive learning: a randomized controlled trial. Ann Surg. 2011;253:886-9.

11. Fann JI, Feins RH, Hicks GL Jr, Nesbitt JC, Hammon JW, Crawford FA Jr, Senior Tour in Cardiothoracic Surgery. Evaluation of simulation training in cardiothoracic surgery: the Senior Tour perspective. J Thorac Cardiovasc Surg. 2012;143:264-72.

12. Kern DE, Thomas PA, Hughes MT. Curriculum Development for Medical Education: A Six-Step Approach. Baltimore, MD: Johns Hopkins University Press; 2009.

13. Trehan K, Kemp CD, Yang SC. Simulation in cardiothoracic surgical training: where do we stand? J Thorac Cardiovasc Surg. 2014;147:18-24.

14. Mokadam NA, Fann JI, Hicks GL, Nesbitt JC, Burkhart HM, Conte JV, et al. Experience with the cardiac surgery simulation curriculum: results of the resident and faculty survey. Ann Thorac Surg. 2017;103:322-8. 
15. Burkhart HM, Riley JB, Hendrickson SE, Glenn GF, Lynch JJ, Arnold JJ, et al. The successful application of simulation-based training in thoracic surgery residency. J Thorac Cardiovasc Surg. 2010;139:707-12.

16. Orr K, Smith M. The financial burden of specialty training. BMJ Careers. June 22, 2016 [Epub ahead of print].

17. Toroser D, DeTora L, Cairns A, Juneja R, Georgieva A, Weigel A, et al. The sunshine act and medical publications: guidance from professional medical associations. Postgrad Med. 2015;127:752-7.
18. Tormey W. Education, learning and assessment: current trends and best practice for medical educators. Ir J Med Sci. 2015;184:1-12.

Key Words: cardiothoracic surgery, curriculum, education, simulation, training courses 